\title{
Editorial
}

\section{Neurodegenerative Diseases: Mechanisms and Therapies}

\author{
Mark A. Smith, ${ }^{1}$ George Perry, ${ }^{1,2}$ Xiongwei Zhu, ${ }^{1}$ and Abdelali Haoudi ${ }^{3}$ \\ ${ }^{1}$ Department of Pathology, Case Western Reserve University, Cleveland, OH 44106, USA \\ ${ }^{2}$ College of Sciences, University of Texas at San Antonio, San Antonio, TX 78249-0661, USA \\ ${ }^{3}$ Department of Microbiology and Molecular Cell Biology, George L. Wright Center for Biomedical Proteomics, \\ Eastern Virginia Medical School, Norfolk, VA 23501, USA
}

Received 11 July 2006; Accepted 11 July 2006

Copyright (c) 2006 Mark A. Smith et al. This is an open access article distributed under the Creative Commons Attribution License, which permits unrestricted use, distribution, and reproduction in any medium, provided the original work is properly cited.

Neurodegenerative diseases are amongst the most costly and devastating diseases, both to patients as well as to their families. This year will mark the 100th anniversary of the first case description of what we now call Alzheimer's disease, the most common neurodegenerative disease. This special time provides a unique opportunity for us to reflect on how much we have learned and yet to also appreciate how much more is left to do to solve this enormous health and social problem. Indeed, there has been an exponential increase in our knowledge of disease mechanisms especially during the past decade: the old doctrine was rejected while new ones arose from its debris. This is a fascinating and, we believe, critical period for novel findings and new ideas to quickly and globally change our understanding of Alzheimer's disease and other neurodegenerative diseases. At this historical time, in this issue of the Journal of Biomedicine and Biotechnology, we have been fortunate to gather some of the foremost thinkers in the field to discuss up-to-date information concerning new developments in this exciting area of research as well as their therapeutic implications. This area of research has attracted some of the most innovative research groups in the field and, as Editors, we are truly privileged that many of these investigators have contributed to this issue. We express our sincerest gratitude to the contributing authors as well as to the vision of the Editor-in-Chief, Dr Abdelali Haoudi, for the opportunity provided by the Journal of Biomedicine and Biotechnology.

Mark A. Smith George Perry Xiongwei $Z$ hu
Mark A. Smith is a Professor of Pathology at Case Western Reserve University, Cleveland, Ohio. He received a B.S. degree in molecular biology and biochemistry from Hatfield College, Durham University, England (1986), and a PhD degree in biochemistry from Nottingham University, England (1990). Following a fellowship at Sandoz Forschungsinstitut, Vienna, Austria, he joined CWRU in 1992. He serves on


the Editorial Boards of many aging-related journals including Age, Aging Cell, and Neurobiology of Aging, and on Review Boards for the NIH and Alzheimer's Association. His research focuses on the pathological mechanism(s) underlying selective neuronal death in neurodegenerative diseases such as Alzheimer's disease. His current work is directed towards elucidating triggers of damaging oxidative stress including fundamental metabolic alterations, homeostatic dysregulation of transition metals, signal transduction alterations, and inappropriate re-entry into the cell cycle. He has authored over 550 peer-reviewed manuscripts and chapters. He is the recipient of several awards including the Ruth Salta Junior Investigator Achievement Award from AHAF, Young Scientist Lectureship Award from the International Society for Neurochemistry, the Nathan Shock New Investigator Award from The Gerontological Society of America, the Jordi Folch-Pi Award from the American Society of Neurochemistry, and the Esterbauer Award from the HNE Society.

George Perry obtained his bachelor of arts in zoology with high honors from the University of California at Santa Barbara in 1974 and his $\mathrm{PhD}$ degree in marine biology from the Scripps Institution of Oceanography, University of California, San Diego, in 1979. After postdoctoral studies in cell biology at Baylor College of Medicine, he joined the Faculty of Case Western Reserve University in 1982 as Assistant Professor

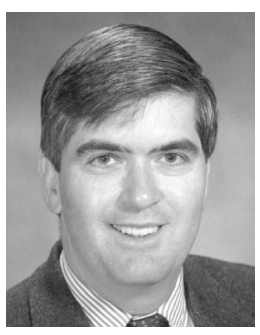
and rose to become Professor in the Departments of Pathology and 
Neurosciences in 1994. In 2006 he was appointed Dean of the College of Sciences, University of Texas at San Antonio. Additionally, he was named Fellow by the American Association for the Advancement of Science in 1998 and is an internationally known Invited Lecturer and has numerous papers, presentations, and publications to his credit. His studies focus on the mechanism of formation and physiological consequences of the cytopathology of Alzheimer's disease. His group has shown that oxidative damage is the initial cytopathological abnormality. His current studies focus on three issues: (i) the metabolic basis for the mitochondrial damage restricted to vulnerable neurons; (ii) the consequences of RNA oxidation on protein synthesis rate and fidelity; and (iii) role of phosphorylation in controlling oxidative adduction.

Xiongwei Zhu is an Assistant Professor of Pathology at Case Western Reserve University, Cleveland, Ohio. He received his BS degree in 1995 and his MS degree in 1998 from the Department of Biochemistry at Wuhan University in China. He received his $\mathrm{PhD}$ degree in 2002 from the Department of Pathology at Case Western Reserve University and became Assistant Professor in 2004. He is the recipient of several awards

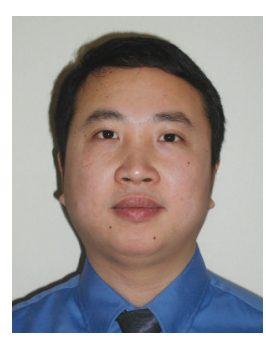
including the International Junior Investigator Award from the International College of Geriatric Psychoneuropharmacology and the Vector Laboratories Young Investigator Award from the International Congress of Histochemistry and Cytochemistry. The focus of his research is on the neurodegenerative mechanisms underlying Alzheimer's disease and other neurodegenerative diseases. Alzheimer's disease is a major public health problem because it has a huge impact on individuals, families, and society and it has attracted increasing public attention as the population ages, which highlights the urgency to understand and treat this disease effectively. This group demonstrated that both oxidative stress and cell cycle-related abnormalities are among the earliest contributors to the disease. The major hypothesis being pursued is that while either oxidative stress or abnormalities in mitotic signaling can independently serve as initiators, both processes are necessary to propagate disease pathogenesis and progression.

Abdelali Haoudi received his $\mathrm{PhD}$ degree in cellular and molecular genetics jointly from Pierre \& Marie Curie University and Orsay University in Paris, France. He then joined the National Institutes of Health (NIEHS, NIH) for a period of four years after winning the competitive and prestigious NIH Fogarty International Award. He then joined the Myles Thaler Center for AIDS and Human Retroviruses at the Uni-


versity of Virginia Medical School, Charlottesville, then shortly after joining the Faculty in the Department of Microbiology and Molecular Cell Biology at Eastern Virginia Medical School in Norfolk, Va, in 2001. He is interested in uncovering mechanisms by which mobile genetic retroelements, both retroviruses and retrotransposons, induce genetic instability and apoptosis in human cells and the molecular basis of cancer including cell cycle checkpoints and DNA repair mechanisms. He is also the Codirector of the Cancer Biology and Virology Focal Group. He has founded the Journal of Biomedicine and Biotechnology (http://www.hindawi.com/GetJournal.aspx?journal=JBB) and is also the Founder and President of the International Council of Biomedicine and Biotechnology (http://www.i-council-biomedbiotech.org). 




The Scientific World Journal
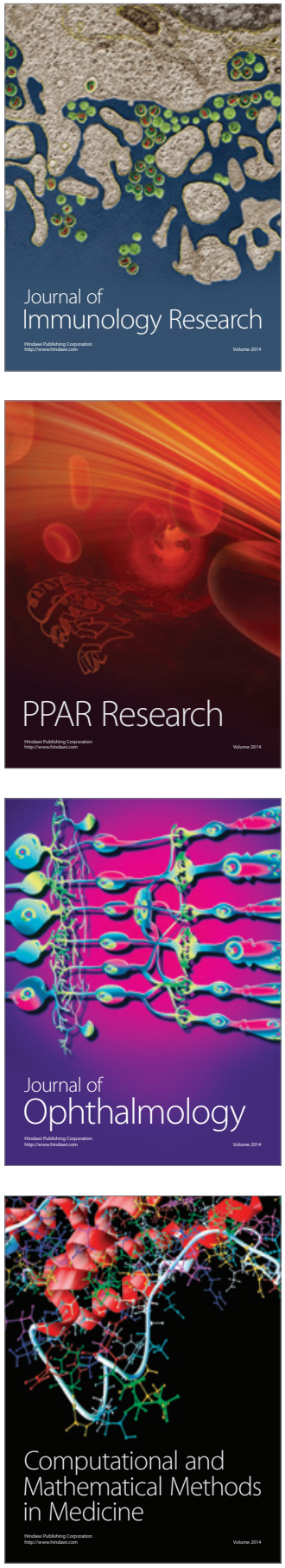

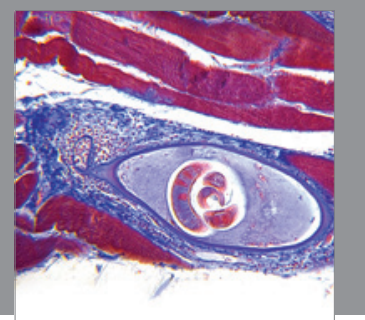

Gastroenterology

Research and Practice
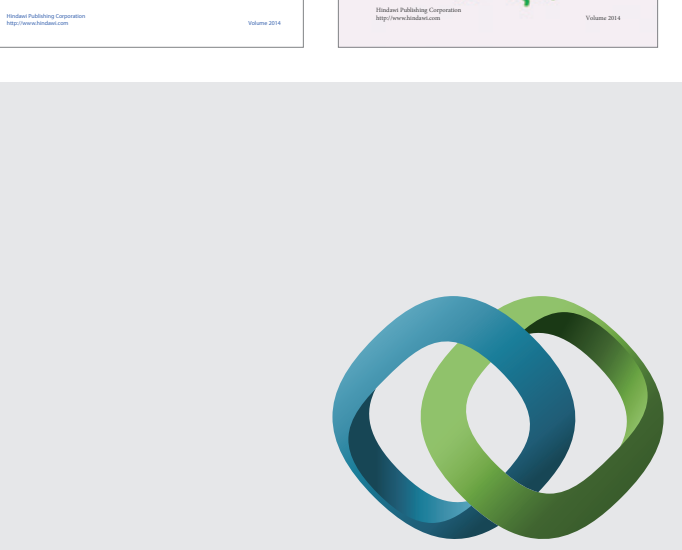

\section{Hindawi}

Submit your manuscripts at

http://www.hindawi.com
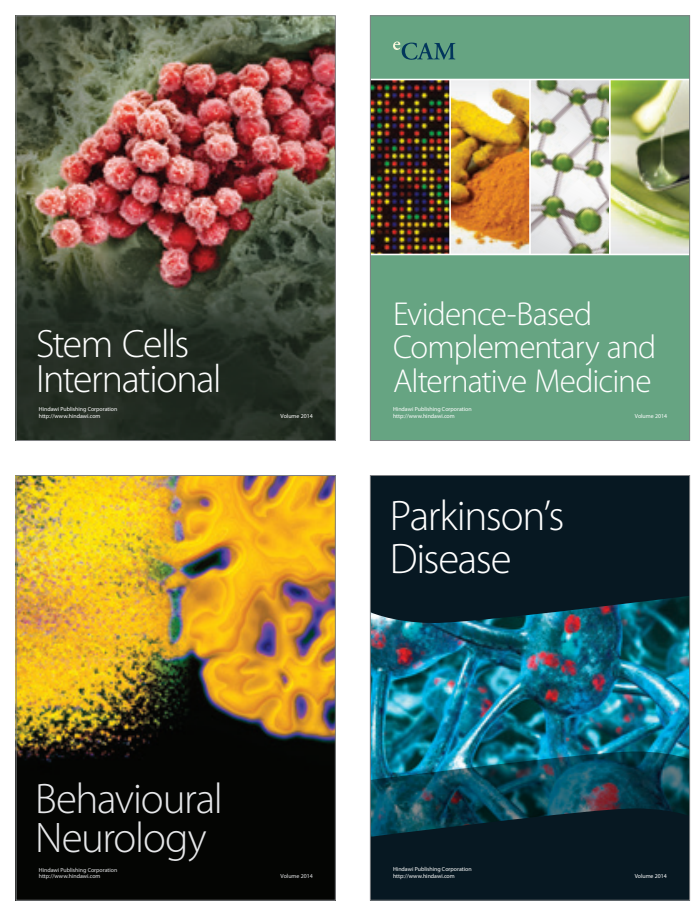

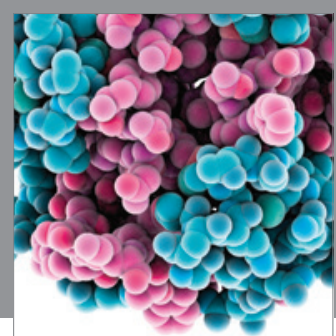

Journal of
Diabetes Research

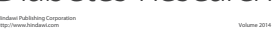

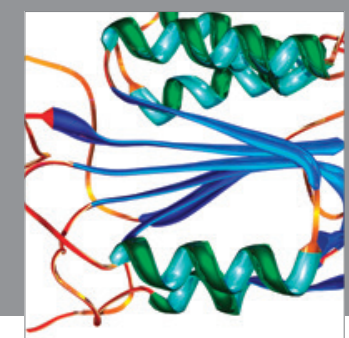

Disease Markers
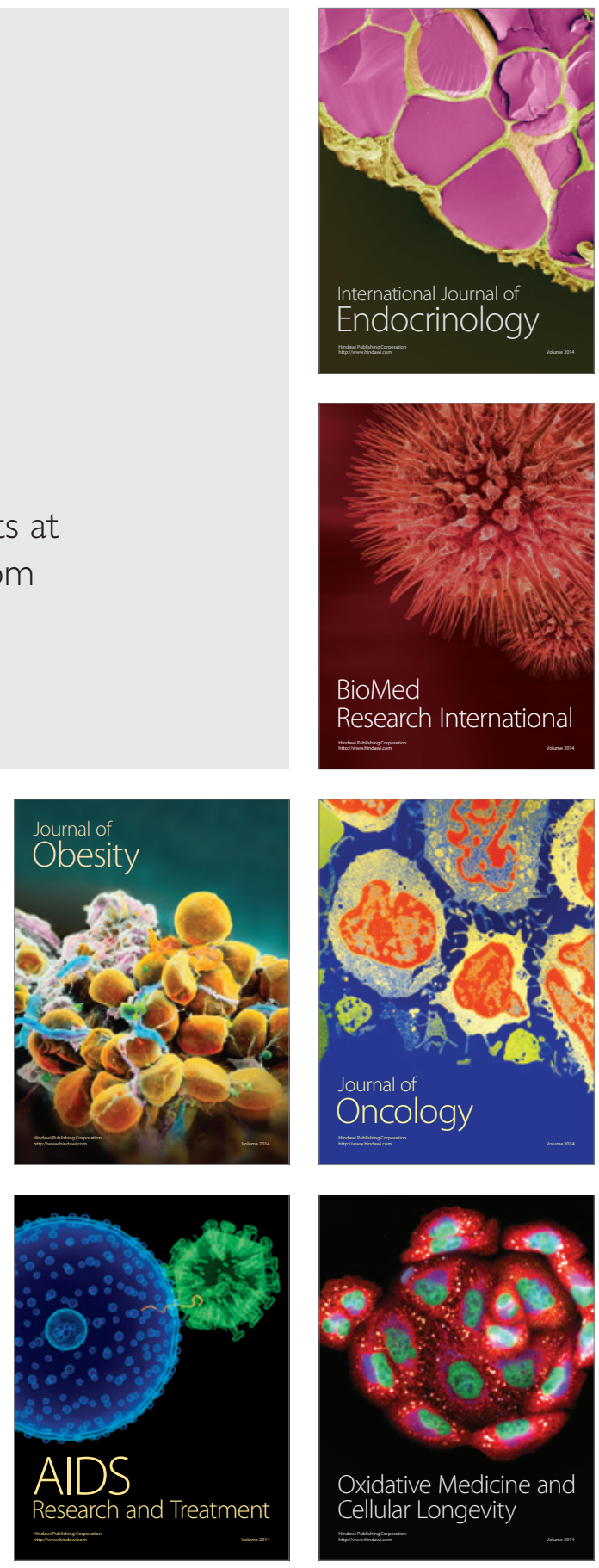